\title{
N-acetylcysteine in the Effective Management of TEN-associated Severe Skin Lesions
}

\author{
Md. Jahidul Hasan ${ }^{1, *}$, Jamia Ahmad ${ }^{2}$, Ahmad Mursel Anam ${ }^{2}$, Raihan Rabbani ${ }^{2}$ \\ ${ }^{1}$ Department of Clinical Pharmacy, Square Hospitals Ltd., Bangladesh \\ ${ }^{2}$ Department of Internal Medicine and ICU, Square Hospitals Ltd., Bangladesh \\ *Corresponding Author: jahidul@squarehospital.com
}

Copyright $\odot 2019$ by authors, all rights reserved. Authors agree that this article remains permanently open access under the terms of the Creative Commons Attribution License 4.0 International License

\begin{abstract}
Adverse drug reaction (ADR) is a serious life-threatening event and toxic epidermal necrolysis (TEN) is a serious ADR where severe skin lesions like, blisters with oral mucosal bleeding (OMB) are most common characteristics. Both watery blisters and OMB are painful conditions in TEN and considered as common source of infections. N-acetylcysteine (NAC) has anti-inflammatory property and the objective of this study was to observe the clinical response of NAC in the TEN-associated lesions management. For this study, we considered 17 patients those were suffering from TEN and admitted in the intensive care unit. Those 17 patients were distributed into 2 groups (A and B), where patients of group-A $(n=7)$ treated with NAC while group-B's patients $(n=10)$ did not get NAC therapy. As a result, in group-A, $6(85.71 \%$; $n=7)$ patients were found with complete remission of blisters and OMB progression within the 72 hours with $100 \%$ 10-day complete healing rate, whereas $60 \%$ patients in group-B $(\mathrm{n}=10)$ required $>72$ hours for complete remission with $80 \%$ 10-day complete healing rate. So, NAC can be an effective therapy for prompt healing of life-threatening TEN-associated severe skin lesions.
\end{abstract}

Keywords Adverse Drug Event, Toxic Epidermal Necrolysis, N-acetylcysteine, Skin Lesions, Intravenous Immunoglobulin

\section{Introduction}

Adverse drug reaction (ADR) is an unpleasant and unpredictable skin reaction to medication that can affect $2-3 \%$ of all hospital admitted patients, which may be up to $8.25 \%$, and among those events, $2 \%$ reactions are severe and become fatal $[1,2]$. The clinical manifestations can range from maculopapular eruptions to severe toxic epidermal necrolysis (TEN). Drug induced TEN is a potentially fatal reaction which is characterized by extensive epidermal and mucosal epithelial destruction, also called Lyell's syndrome [2, 3]. TEN can be triggered by some common drugs including antibiotics, CNS depressants, antiepileptics and so on. A study in Germany showed that among all TEN incidences, $40 \%$ were antibiotics-induced and analgesics were responsible for $23 \%$ of cases in each year [4]. FDA AERS database showed that among a million American people, 1.9 cases of TEN reported in every year [5].

The exact mechanism behind drug-induced TEN is not completely clear till today and is considered as a biochemically complex immune-mediated reaction. Clinical, histopathological and immunological analysis of TEN lesions found that necrosis-induced keratinocyte apoptosis is the basic pathogenesis of extensive epidermal detachment happened in TEN. Recent scientific findings elucidated that Fas ligand (FasL) is the basic responsible factor for apoptotic cell death in TEN [6].

Treatment of drug induced TEN is still a controversial approach and controversial intravenous corticosteroid therapy is widely used. The role of intravenous immunoglobulins (IVIG) as a immune booster in TEN is a matter of debate and the use of $\mathrm{N}$-acetylcysteine (NAC) in TEN is a very new concept, globally $[10,18]$. Till today, the primary supportive management of drug induced TEN has not yet been scientifically established. The main objective of this study was to observe the therapeutic outcome of using NAC in the management of TEN-associated severe skin lesions.

\section{Materials and Methods}

This prospective observational study was operated in a tertiary level hospital of Dhaka, Bangladesh and continuously conducted for 12 months (July, 2017 to June, 2018). During the study period, 21 patients were admitted in the adult Intensive Care Unit (ICU) with drug-induced TEN and all those patients had different sized blisters on skin all over the body. After admitting in ICU, all the ADR-related culprit drugs were identified and it was 
assured that none of those was present currently in patients' medication lists. Among those 21 patients, initially 2 patients were discontinued from the study (one patient died within 24 hours after admitting in ICU and another patient came from another hospital where he got the initial treatment for TEN and skin lesions). As per the method of the study, all the 19 patients with TEN were distributed one after the other into two groups: group-A (NAC group) and group-B (non-NAC group) during the time of ICU-admission, and in this way, group-A contained 9 patients and group-B contained 10 patients, accordingly. During the study period, 2 patients of group-A were shifted to other hospitals without completing the treatment and they were expelled from the study. Finally, study was completed with 7 patients in group-A and 10 patients in group-B.

After getting admission in ICU with TEN-associated blisters and oral mucosal bleeding, NAC (600 mg, intravenously, 8-hourly) therapy was incorporated without any delay in the prescriptions of all patients of group-A for the blisters and oral mucosal bleeding management, whereas patients of group-B treated with neither NAC nor any other specific drug for that purpose. TEN-specific severity-of-illness score (SCORTEN) is parameter used in ICU for assessing the severity of illness of the patients with TEN and SCORTEN was calculated for every patients of both the groups (A and B). After 48 hours, the overall healing status of the blisters of all the patients of both groups was recorded. All the patients of both groups (A and $\mathrm{B} ; \mathrm{N}=17)$ received IVIG ( $1 \mathrm{~g} / \mathrm{Kg}$ of body weight/day for 2 doses in 2 consecutive days) in the beginning of the treatment as a common drug. The ethical approval for this study from the hospital ethical committee was taken on May, 2017. All the data of this study were analyzed by using IBM SPSS statistics (version 22) software.

\section{Results}

All the patients of both the groups (A and B) were young and middle aged. The median age of patients was 47 and 53.5 for group-A and $-\mathrm{B}$, respectively (Table 1 ). Male and female patient ratio in both groups was described in table 1 . The minimum and maximum SCORTEN values for
group-A were 4 and 6 , respectively with a mortality rate $90 \%$ (median was 5 ) whereas for group-B, minimum and maximum SCORTEN values were same as group-A, but the median was 4 with a mortality rate $58.3 \%$ (table 1 ).

Table 1. Characteristics of the patients and related variables

\begin{tabular}{lcc}
\hline \multirow{2}{*}{ Characteristics } & \multicolumn{2}{c}{ Variables } \\
\cline { 2 - 3 } Age (year) & $\begin{array}{c}\text { Group-A } \\
(\mathbf{n}=\mathbf{7})\end{array}$ & $\begin{array}{c}\text { Group-B } \\
(\mathbf{n}=\mathbf{1 0})\end{array}$ \\
\hline Median & 47 & 53.5 \\
\hline Range (min-max) & $16-57$ & $21-62$ \\
\hline Gender & & 7 \\
\hline Male & 5 & 3 \\
\hline Female & 2 & 4 \\
\hline SCORTEN value & & $4-6$ \\
\hline Median & 5 & 58.30 \\
\hline Range (min-max) & $4-6$ & $50.30-90.0$ \\
\hline Mortality rate (\%) & & \\
\hline Median & 90 & \\
\hline Range (min-max) & $58.30-90.0$ & \\
\hline & & \\
\hline
\end{tabular}

In group-A, patients $(n=7)$ were specifically treated with NAC for their blisters and oral mucosal bleeding (OMB) and among them, 6 patients $(n=7 ; 85.71 \%)$ were found with no further progression of their blisters and OMB within 48 hours and drying symptoms was noticed, whereas only 1 patient $(10 \%)$ in group-B $(n=10)$ was found with drying symptoms in the blisters and $\mathrm{OMB}$ (table 2). Progression of blisters and OMB was stopped in $30 \%(3 ; n=10)$ patients of group-B within 72 hours, and the majority of patients $(6 ; 60 \% ; n=10)$ were found with no further progression of their blisters and OMB after 72 hours of admission (table 2). On the other hand, all the patients of group-A $(\mathrm{n}=7)$ were found with complete remission from blisters and OMB progression by 72 hours (mentioned in table 2). In a 10-day complete blister and OMB healing rate comparison, all the patients of group-A showed $100 \%$ healing ( 7 out of 7 patients) while $80 \%$ patients (8 out of 10 patients) of group-B were found with complete healing of the lesions (table 2).

Table 2. Comparison of progression of healing (blisters and oral mucosa)

\begin{tabular}{ccccc}
\hline Group & $\begin{array}{c}\text { Progression of blisters and } \\
\text { OMB* stopped within 48 } \\
\text { hours } \\
\mathbf{n}, \%\end{array}$ & $\begin{array}{c}\text { Progression of blisters and } \\
\text { OMB* stopped within } \mathbf{7 2} \\
\text { hours } \\
\mathbf{n}, \%\end{array}$ & $\begin{array}{c}\text { Progression of blisters and } \\
\text { OMB* stopped in }>\text { 72 hours } \\
\mathbf{n}, \%\end{array}$ & $\begin{array}{c}\text { 10-day complete } \\
\text { blister and OM* } \\
\text { healing rate } \\
\mathbf{n}, \%\end{array}$ \\
\hline $\mathrm{A}(\mathrm{n}=7)$ & $6(85.71)$ & $1(14.29)$ & - & $7(100)$ \\
\hline $\mathrm{B}(\mathrm{n}=10)$ & $1(10)$ & $3(30)$ & $6(60)$ & $8(80)$ \\
\hline
\end{tabular}

OMB*: oral mucosal bleeding; $\mathrm{OM}^{*}$ : oral mucosal 


\section{Discussion}

TEN can be generated by a single drug with a number of critical characteristics such as acute mucocutaneous reaction with its different degree of severity [3]. TEN is a life threatening event mostly characterized by severe lesions with scattered 2-ring target having a dark-red center, thin red halo with central blistering that can spread to vast areas of denuded skin. In addition, often found hemorrhagic mucositis in mouth, eyes, genital organs and respiratory tract, and some systemic symptoms like, hyperthermia [11]. In our study, the use of NAC in group-A's patients carried out a very effective outcome in minimizing the progression of painful lesions, such as blisters on skin and oral mucosal bleeding with a very fast response (complete remission of the progression of blisters and OMB within 72 hours in all patients; $n=7$ ) in comparison to the patients of group-B ( no NAC therapy introduced).

In order to accurately predict the mortality in patient with TEN, a disease severity measuring scale, also known as SCORTEN (TEN-specific scale) is used worldwide and this scale has seven fixed independent risk factors (age, presence of malignancy, body surface area involved, serum urea nitrogen level, glucose level, bicarbonate level and heart rate) for calculating a digit in the scale [12]. The factors that can greatly affect the rate of mortality in patients with TEN are the presence of severe infections, such as septicemia during hospitalization time or even in the early few hours of hospitalization, age of the patient and total affected body surface area [13]. The SCORTEN value for every patient of both the groups was calculated within the first hour of the admission in ICU and this score gave an impression about the current severity-status. During a TEN event, multiple co-factors can contribute as triggering factors to enhance the TEN-associated complications and patient's physiological conditions may be significantly deteriorated with a short period [2]. In a study, researchers found that in $74 \%-94 \%$ TEN-associated cases, present complications were triggered by preceding medication of the prescription or mostly, by upper respiratory tract infections. In the same study, more than 100 enlisted drugs were identified those were responsible for TEN-incidences and among those, the most common culprit class of drugs was antibiotics [4].

Scientists believed that keratinocytes undergo apoptosis through multiple phases. Phase-I is involved with the immunogenic role of xenobiotics. Phase-II expresses the early apoptosis process and that possesses the production of strongly electrophilic metabolites that disrupt the electron transfer chain in the mitochondria and generated reactive oxygen species (ROS) working as second messengers can enhance the gene transcription process of the TNF- $\alpha$ and CD95 proapoptotic systems [6]. In phase-III, the cytokine TNF- $\alpha$ works as an autocrine factor on neighbouring sound cells and spread epidermal destruction. In the late phase-IV, through a slow nonapoptotic mechanism, disrupted cells with ruptured mitochondria are necrotized, finally [13].

The discovery of Fas ligand (FasL) opened a new approach to apoptotic cell death in TEN. Binding of FasL to Fas activates the release of caspases that play essential role in programmed apoptotic cell death [7]. Fas is distributed ubiquitously in a variety of cells and in keratinocytes, FasL is found to be responsible for the activation of natural killer cell (NK cell) and cytotoxic T-cell (CD8) that release perforin and granzyme B [8]. Even scientists found that FasL is also observed in keratinocytes of TEN lesions [6]. To date, scientific evidences suggest that FasL and granulysin are the major molecules accountable for keratinocyte apoptosis in TEN $[6,9]$.

Till today, there is no specific recommended treatment paradigm for TEN, globally. Hence, withdrawal of the suspected culprit drug and simultaneously, an integrated supportive care is necessary to minimize the severity of TEN and the related lesions [14].

A study showed that in patients with TEN having $44.8 \%$ epidermal detachment, $88 \%$ survival rate is observed because of using IVIG in the right time with proper supportive care and IVIG potentially inhibited Fas-mediated cell death [15]. Another study mentioned that as TEN-patients are very much susceptible to secondary infections, IVIG infusion therapy through its anti-infective properties may reduce the chance of infections [16]. In 2006, a review study considering 14 studies on TEN-patients found that in majority of cases, researchers observed good satisfactory results with intravenous IVIG, while three cohort studies found less improvement with IVIG [17]. In our study, IVIG ( $1 \mathrm{~g} / \mathrm{Kg}$ body weight, for 2 doses in 2 consecutive days) was given to all patients of both the groups in the first hour of ICU-admission.

Acetylcysteine, also known as N-acetylcysteine (NAC), a cysteine derivative, has the ability to boost the level of Glutathione (GSH) and thus shows its anti-inflammatory action. Several factors can affect the detoxifying capacity of glutathione and its release phenomenon. When NAC is administered, it potentiates the oxidant buffering ability of Glutathione and inhibits kappa-B, a nuclear transcription factor that is inaugurated by tumor necrosis factor- $\alpha$ and interleukin-6 in the cell. In few open-label studies, a number of TEN-patients recovered well with high-dose intravenous NAC $[18,19]$. In our study, NAC responded well in the management of skin-lesions and all skin-lesions in the patients of group-A $(100 \% ; n=7)$ including OMB were healed completely within 10 days because of the clinical role of NAC. More studies are required to evaluate the significant therapeutic roles of NAC and the absolute physiological mechanism behind this effect in TEN-associated blisters and OMB management.

\section{Conclusions}

TEN is a serious adverse drug reaction which can turn 
into a life threatening event when associated with bacterial infections, severe dehydration, visceral bleeding and so on. Both watery skin blisters and oral mucosal bleeding were painful physical sequences in TEN and lives can be saved by incorporating early effective treatment. The use of intravenous $\mathrm{N}$-acetylcysteine in the management of blisters and oral mucosal bleeding is an effective treatment tool and additionally should be given with IVIG in the early stage of detection of TEN.

\section{Conflicts of Interest}

No conflicts of interest.

\section{Funding}

This work was supported by no external funding source.

\section{Acknowledgements}

All authors of this study are very grateful to all ICU doctors and authority of Square hospital because of their permission for this study and all kind of cooperation as well as time to time supports during the study.

\section{REFERENCES}

[1] Mani MZ, Mathew M. A study of 218 drug eruptions. Indian J Dermatol Venereol Lepr. 1983; 49:109-17.

[2] Noel MV, Sushma M, Guido S. Cutaneous adverse drug reactions in hospitalized patients in a tertiary care centre. Indian J Pharmacol. 2004; 36:292-5.

[3] Revuz J. Alan Lyell and Lyell's syndrome. J Eur Acad Dermatol Venereol. 2008; 22(8):1001-2.

[4] Schopf E, Stuhmer A, Rzany B, Victor N, Zentgraf R, Kapp JF. Toxic epidermal necrolysis and Stevens-Johnson syndrome: an epidemiologic study from West Germany. Arch Dermatol. 1991; 127(6): 839-42.

[5] La Grenade L, Lee L, Weaver J, Bonnel R, Karwoski C, Governale L, Brinker A. Comparison of reporting of Stevens-Johnson syndrome and toxic epidermal necrolysis in association with selective COX-2 inhibitors. Drug Saf. 2005; 28:917-924.

[6] Viard I, Wehrli P, Bullani R, Schneider P, Holler N, Salomon D, Hunziker T, Saurat JH, Tschopp J, French LE.
Inhibition of toxic epidermal necrolysis by blockade of CD95 with human intravenous immunoglobulin. Science. 1998; 282:490-93.

[7] Nagata S. Apoptosis by death factor. Cell. 1997; 88:355-65.

[8] Iwai K, Miyawaki T, Takizawa T, Konno A, Ohta K, Yachie A, Seki H, Taniguchi N. Differential expression of bcl-2 and susceptibility to anti-Fas-mediated cell death in peripheral blood lymphocytes, monocytes, and neutrophils. Blood. 1994; 84:1201-8

[9] Chung WH, Hung SI, Yang JY, Su SC, Huang SP, Wei CY, Chin SW, Chiou CC, Chu SC, Ho HC. et al. Granulysin is a key mediator for disseminated keratinocyte death in Stevens-Johnson syndrome and toxic epidermal necrolysis. Nat Med. 2008; 14:1343-50.

[10] French LE. Toxic epidermal necrolysis and Stevens Johnson syndrome: our current understanding. Allergol Int. 2006; 55:9-16.

[11] Revuz J, Penso D, Roujeau JC, Guillaume JC, Payne CR, Wechsler J, Touraine R. Toxic epidermal necrolysis. Clinical findings and prognosis factors in 87 patients. Arch Dermatol. 1987; 123(9):1160-5.

[12] Bastuji-Garin S, Fouchard N, Bertocchi M, Roujeau JC, Revuz J, Wolkenstein P. Scorten: a severity-of-illness score for toxic epidermal necrolysis," J Invest Dermatol. 2000;115(2):149-53.

[13] Green DR, Reed JC. Mitochondria and apoptosis. Science. 1998; 281(5381):1309-12.

[14] Garcia-Doval I, LeCleach L, Bocquet H, Otero XL, Roujeau JC. Toxic epidermal necrolysis and Stevens-Johnson syndrome: does early withdrawal of causative drugs decrease the risk of death? Arch Dermatol. 2000; 136(3):323-7.

[15] Prins C, Kerdel FA, Padilla RS, Hunziker T, Chimenti S, Viard I, Mauri DN, Flynn K, Trent J, Margolis DJ, Saurat JH, French LE. Treatment of Toxic Epidermal Necrolysis With High-Dose Intravenous Immunoglobulins: Multicenter Retrospective Analysis of 48 Consecutive Cases. Arch Dermatol. 2003; 139(1):26-32.

[16] Dwyer JM. Manipulating the immune system with immune globulin. N Engl J Med. 1992; 326107-16.

[17] Mittmann N, Chan B, Knowles S, Cosentino L, Shear N. Intravenous immunoglobulin use in patients with toxic epidermal necrolysis and Stevens-Johnson syndrome. Am J Clin Dermatol. 2006; 7(6):359-68.

[18] Velez A, Moreno JC. Toxic epidermai necrolysis treated with N-acctylcysteine. J Am Acad Dermatol. 2002; 46(3):469-70

[19] Redondo P, de Felipe I, de la Peña A, Aramendia JM, Vanaclocha V. Drug-induced hypersensitivity syndrome and toxic epidermal necrolysis. Treatment with $\mathrm{N}$-acetylcysteine. Br J Dermatol. 1997; 136(4):645-6. 